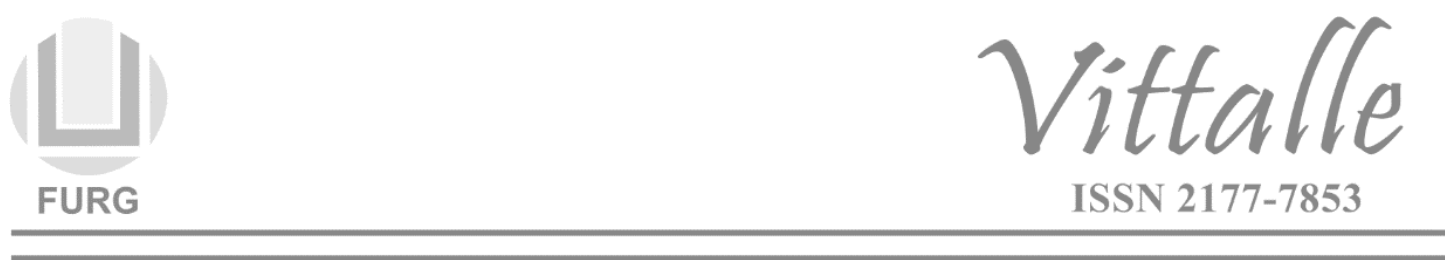

\title{
Acesso Venoso e Punção Arterial
}

\author{
Ana Luisa Canova Ogliari ${ }^{\mathrm{a},}$, Cleuber Gea Martins Filho ${ }^{\mathrm{b}}$ \\ ${ }^{\text {a }}$ Universidade Federal do Rio Grande, Rio Grande, RS, Brasil \\ ${ }^{\text {b }}$ Pontifícia Universidade Católica do Rio Grande do Sul - PUCRS, Porto Alegre, RS, Brasil
}

\section{Palavras-chave: \\ Circulação sanguínea; \\ Gasometria; Infusões \\ intra-arteriais; Injeções intra-arteriais; Veia subclávia; Pressão venosa.}

Keywords:

Blood circulation; Blood gas analysis; Infusion, Intra-arterial; Injection, intra-arteriais; Subclavian vein; Venous pressure.

\section{RESUMO}

$\mathrm{O}$ acesso vascular é fundamental para a administração parenteral de fluidos ou medicamentos. Dessa forma, além de outros profissionais da saúde, cabe também ao médico o conhecimento da técnica e a capacidade de realizar esse procedimento. É importante salientar que existem dois principais tipos de acesso: o periférico e o central, os quais devem ser escolhidos devido a características que serão abordadas ao longo desse capítulo. Existe também a opção do acesso intraósseo, o qual também será brevemente relatado neste capítulo, bem como punções arteriais.

Venous Access and Arterial Puncture

\section{ABSTRACT}

Vascular access is essential for the parenteral administration of fluids or medications. Thus, it is up to the physician and other health professionals to know the technique and the ability to perform this procedure. It is important to note that there are two main types of access: the peripheral and the central, which must be chosen due to characteristics that will be addressed throughout this chapter. There is also the option of intraosseous access, which will also be briefly reported in this chapter, as well as arterial punctures.

\section{Introdução}

Este capítulo abordará detalhes técnicos e práticos acerca dos acessos vasculares mais comuns, destacando-se o acesso venoso periférico, acesso venoso central, acesso intraósseo e acesso arterial para coleta de gasometria.

\section{Acesso Venoso Periférico}

O acesso venoso periférico é aquele realizado em veias periféricas dos membros superiores ou inferiores proporcionando uma via de acesso rápida ao sistema circulatório do paciente $(1,2)$ e utilizada quando a via oral não é possível (3). Normalmente, dá-se preferência para as veias de grosso calibre e com trajeto retilíneo devido à facilidade do acesso e a possibilidade de maior infusão de fluidos $(1,3)$.

\subsection{Local de escolha}

Para escolha do melhor local de punção deve-se observar alguns fatores, entre eles $(1,2,4)$ :

\footnotetext{
* Autor correspondente: analuisa_canovaogliari@hotmail.com (Ogliari, A.L.C.).
} 
- Idade;

- Conforto;

- $\quad$ Facilidade de acesso da veia;

- Áreas livres de tatuagens;

- Locais com menor presença de pelos;

- Locais que não tenham sido recentemente puncionados;

- Veia com trajeto mais retilíneo;

- Situação em que se encontra o paciente;

- Urgência da situação.

Normalmente, o local de primeira escolha são as veias dos membros superiores, pois são os que proporcionam acessos mais duráveis e se associam à menores complicações (4). As veias dos membros inferiores também podem ser utilizadas para punção periférica, porém são escolhidas apenas quando outros locais não estão disponíveis, devido ao aumento do risco de tromboflebite (1).

\subsubsection{Membros superiores $(1,2,4,5)$}

Na mão, utiliza-se as veias basílica, cefálica e a veia dorsal metacarpiana (2).

No braço e antebraço escolhe-se as veias cefálica, basílica e cubital mediana. Salientase que a fossa cubital proporciona uma melhor apresentação e possui veias de maior calibre, sendo um local bastante utilizado, principalmente para punções de menor duração $(1,2)$.

\subsubsection{Membros inferiores}

Deve-se optar nessa região pelas veias safena ou dorsal do pé $(1,2,5)$.

\subsection{Indicações $(1,4)$}

- $\quad$ Coleta de sangue periférico;

- $\quad$ Administração intravenosa de medicamentos;

- Transfusão de hemoderivados;

- Infusão de fluidos e hemoderivados em cirurgias;

- Atendimento de emergência, com paciente em choque ou politraumatizado;

- Qualquer outra solução com indicação intravenosa.

\subsection{Contraindicações $(1,4)$}

- Hiperemia no local,

- Flebite;

- Esclerose de veias;

- Infiltração intravenosa prévia;

- Fístula arteriovenosa no membro;

- Lesões no local da punção como infecções, queimaduras e lesões traumáticas, por exemplo.

\subsection{Vantagens (4)}

Acesso rápido e seguro, com mínimo risco de complicações para o paciente. Pode ser realizado mesmo na vigência de alterações da coagulação, pesando-se o risco e benefício. 


\subsection{Desvantagens (4)}

Necessidade de troca de cateteres a cada 72 horas a fim de evitar infecções.

\subsection{Escolha do cateter (1-5)}

O tamanho do cateter depende da função, local e tamanho do vaso e idade do paciente (1).

Butterflies: São cateteres metálicos que oferecem menor resistência ao fluxo de infusão e se associam, geralmente, a menores riscos de complicações. Devem ser utilizados em situações que a infusão ocorrerá por pouco tempo, pois neste tipo de dispositivo a agulha permanece dentro da veia podendo causar lesões (2). Não devem ser utilizados para reposição volêmica (4). Esses dispositivos são numerados em números ímpares do número 19 (agulha maior e mais calibrosa) ao número 27 (agulha menor e menos calibrosa) (2). Para punção com Butterfly a angulação inicial deve ser de $15^{\circ}$ e depois a $10^{\circ}$, com o bisel sempre para cima (4).

Jelcos: Mais conhecido pelo nome comercial de Abocath, são cateteres utilizados quando há indicação de reposição volêmica (4). Em caso de necessidade de rápido fluxo, deve-se dar preferência aos cateteres curtos e calibrosos, pois infundem mais volume em menos tempo. Os jelcos são dispositivos em que a agulha é envolvida por um cateter flexível e, após a punção, a agulha é retirada ficando na luz da veia apenas esse cateter. Esses dispositivos são numerados em números pares do número 14, o qual é o maior e mais calibroso até o número 24, que é o menor e mais fino(2). Para punção, angula-se o Jelco, inicialmente a $15^{\circ}$, passando para $10^{\circ}$, com o bisel para cima. Ao acessar a luz do vaso, a agulha e deixada fixa e o cateter e deslizado por cima dela, sendo a agulha retirada ao final (4).

\subsection{Técnica $(1,2,4)$}

Materiais necessários

- Bandeja;

- Luvas de procedimento;

- Óculos de proteção;

- Garrote elástico;

- Dânula ou extensor;

- Solução antisséptica;

- Gaze estéril;

- Solução fisiológica;

- Curativo oclusivo transparente estéril;

- Esparadrapo ou micropore;

- Cateteres de tamanho apropriado;

- Bolsa de soro com equipo ou seringa de $10 \mathrm{ml}$ para salinizar o acesso;

- Etiqueta para identificação.

Procedimento $(1,2,4)$

- Higienizar as mãos, separar os materiais necessários, explicar o procedimento ao paciente e calçar luvas de procedimento;

- Aplicar garrote elástico em porção proximal do membro, aproximadamente 5 a 10 
cm acima do local da punção para proporcionar a dilatação da veia;

- Selecionar o local apropriado para a punção, inspecionando-a e visualizando a porção mais retilínea da veia. Caso haja dificuldade na evidenciação da veia, pode-se solicitar que o paciente abra e feche a mão repetidamente, também pode-se colocar uma compressa morna sob o braço. Existe também a possibilidade de utilizar ultrassom, no entanto sua utilização depende da disponibilidade no aparelho;

- Realizar a antissepsia do local escolhido, com solução antisséptica. Deve-se realizar a limpeza do local com movimentos circulares, do centro para as extremidades, deixando a área secar completamente;

- Puncionar a veia com o bisel da agulha voltado para cima em ângulo de 30 graus. Depois, deve-se diminuir o ângulo para 10 a 15 graus, observando se há refluxo de sangue, pois isso indica a posição correta, ou seja, constata que a agulha está no lúmen da veia. Importante salientar que quanto mais superficial a veia, menor o ângulo de introdução da agulha;

- Introduzir o cateter na veia e remover a agulha (caso esteja sendo usado um jelco) e, após, remover o garrote elástico;

- Colocar a dânula ou o extensor na extremidade do cateter;

- Fixar o cateter e o equipo à pele, com curativo oclusivo transparente e estéril, fixando o equipo em alça e anotando a data do curativo;

- Deve-se injetar soro fisiológico para confirmar que o cateter está pérvio e bem posicionado. Observar ocorrência de edema, vermelhidão, ou desconforto importante do paciente;

- Coletar amostras de sangue para realização de exames iniciais do paciente;

- Conectar o cateter ao equipo de infusão, caso haja necessidade de infusão de fluidos ou conectar a seringa para injetar o medicamento necessário. Importante calcular a necessidade a ser infundida de fluido ou medicamento e ajustar o gotejamento;

- Dispensar os materiais utilizados nos locais adequados de descarte, retire as luvas e higienize as mãos.

\subsection{Complicações mais frequentes $(1,4)$}

- Dor;

- Formação de equimose ou hematoma;

- Infecções;

- Extravasamento de fluidos e drogas;

- Flebite;

- Trombose;

- Lesão nervosa.

\section{Acesso Venoso Central}

O acesso venoso central é aquele realizado em veias centrais, proporcionando acesso à circulação sistêmica através do posicionamento de um dispositivo apropriado para o acesso vascular cuja extremidade atinja a veia cava superior ou inferior (7). Esse acesso permite a administração de fluidos, nutrientes, sangue e derivados, medicações e outras substâncias que poderiam lesar tecidos se fossem injetadas em veias periféricas, como os vasopressores e soluções hipertônicas de bicarbonato de sódio e cálcio (1,3). Além disso, permite a monitorização da pressão venosa central e a coleta de amostras de sangue (1). O acesso central é um procedimento que deve ser realizada pelo médico ou profissional habilitado, pois exige maior habilidade e tem potencial de complicações mais graves $(5,6)$. 


\subsection{Local de escolha (6-8)}

A escolha pelo local da punção geralmente se dá de acordo com a experiência de quem realizará o procedimento e as características do paciente. Normalmente, a veia subclávia direita é a primeira opção, no entanto, em casos de parada cardiorrespiratória (PCR) a via femoral pode ser a escolha por não influenciar nas manobras de RCP (1). Deve-se atentar para as contra indicações e complicações inerentes de cada local a ser escolhido (9).

\subsection{Indicações $(1,3,5-12)$}

- Impossibilidade de punção de veias periféricas;

- Necessidade de monitorização hemodinâmica invasiva (pressão venosa central, pressão de artéria pulmonar, débito cardíaco por termodiluição);

- Suporte para infusão rápida de fluidos durante ressuscitação ou cirurgia;

- Administração de soluções hipertônicas, cáusticas ou irritantes;

- Utilização de drogas vasoatiavas;

- Terapêutica substitutiva renal de urgência (hemofiltração, hemodiálise);

- Acesso vascular de longo prazo para nutrição parenteral prolongada ou quimioterapia.

\subsection{Contraindicações $(1,6-8,11)$}

- Infecções ou lesões na área de punção;

- Trombose no trajeto do vaso.

As coagulopatias entram como contraindicações relativas, pois se deve avaliar o risco/benefício do procedimento. Importante ressaltar que não devem ser a primeira escolha em politraumatizados pelos riscos inerentes ao procedimento. Além disso, o trauma pode distorcer a anatomia do local, dificultando a punção (1).

\subsection{Vantagens $(6,7,11)$}

- Maior vida útil em comparação aos cateteres periféricos;

- Possibilidade de monitorização hemodinâmica invasiva;

- Possibilidade de administração de solução de alta osmolaridade.

\subsection{Desvantagens $(6,7,11)$}

- Maiores riscos inerentes à introdução da agulha às cegas, como pneumotórax, hemotórax e quilotórax;

- Maiores complicações em relação à permanência do cateter, como trombose ou infecção levando a septicemia;

- Em estado hipovolêmico, a veia jugular interna tende a colabar, tornando difícil a sua localização com a agulha de punção, especialmente no procedimento às cegas;

- A punção torna-se difícil em pacientes com pescoço curto e em obesos.

\subsection{Escolha do cateter $(1,6-8,11)$}

A escolha deve ser baseada na indicação de acesso, avaliando as necessidades de cada paciente. Geralmente, dá-se preferência para a punção em veias centrais à direita, pois as 
complicações como pneumotórax, hemotórax e quilotórax são mais frequentes em tentativas no lado esquerdo, pois o ápice do pulmão esquerdo é mais alto e o ducto torácico localiza-se neste mesmo lado (1).

Pode-se utilizar um cateter de nome comercial Intracath, pois o cateter passa pelo interior da agulha. Assim, após a punção, a agulha permanece no lúmen da veia. É um cateter de menor custo, entretanto necessita de agulhas mais calibrosas com maior risco de danos (6).

Já a opção mais utilizada é a realizada através da técnica de Seldinger, na qual se utiliza um fio guia metálico que é introduzido através da agulha no lúmen da veia. Então, a agulha é retirada e procede-se a dilatação do trajeto com o dilatador (Figura 1). Por fim, retira-se o dilatador e introduz-se o cateter através do fio guia que é retirado após a completa colocação do cateter $(1,6-8)$. Esse é um cateter de maior custo, mas dispõe de agulhas mais delicadas o que diminui o risco de lesão da veia puncionada (6).
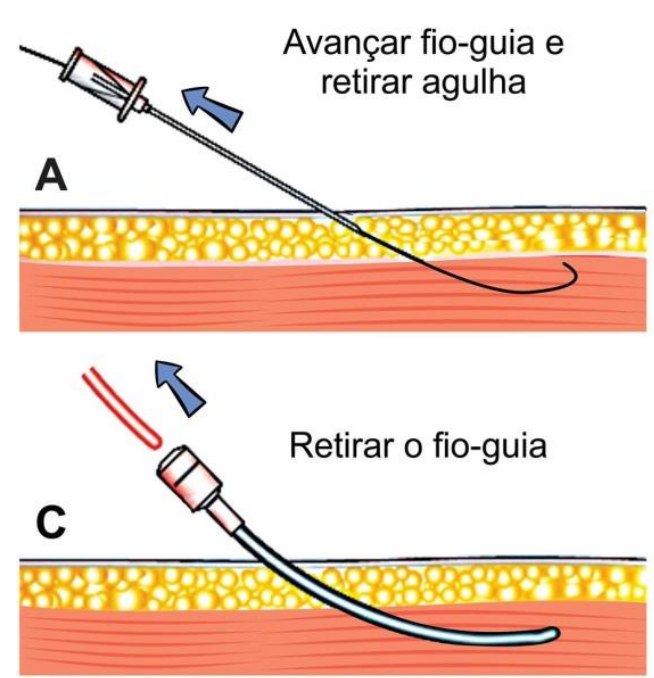

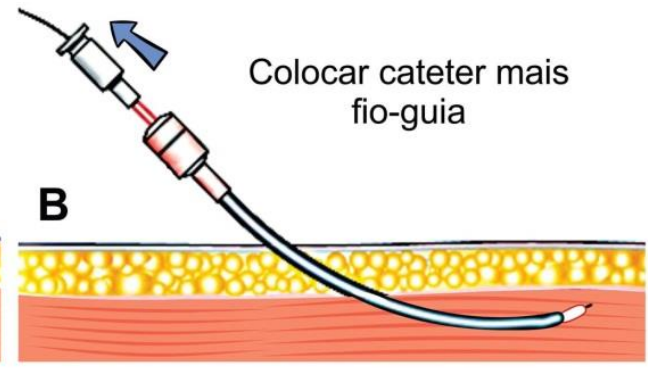

Fixar o cateter

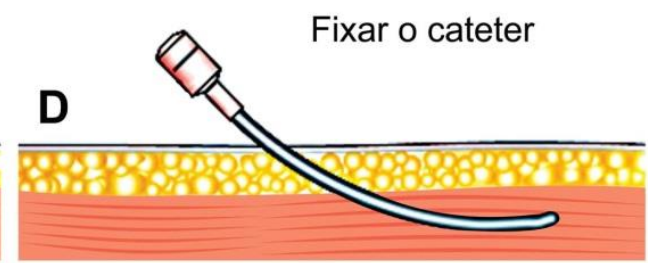

Figura 1 - Técnica de Seldinger para punção percutânea. (A) Puncionar vaso, introduzir fio-guia e retirar a agulha; (B) Avançar o cateter vestindo o fio-guia para dentro do vaso; (C) Retirar o fio-guia. (D) Fixar o cateter em posição. Fonte: Elaborado por Gabriel Rigatti e Daniel Audino

\subsection{Técnica $(1,6-8,11)$}

Materiais necessários:

- Luvas assépticas;

- Óculos de proteção;

- Avental cirúrgico estéril;

- Touca e máscara;

- Campos estéreis;

- Gazes estéreis;

- Bolsa e equipo do soro;

- Anestésico local;

- Agulha e fio para fixação do cateter;

- Curativo;

- Kit de cateter central contendo agulha, fio guia, dilatador e cateter intravenoso. Esse kit será necessário quando a técnica a ser realizada for a de Seldinger. 


\section{Procedimento: Técnica de Seldinger}

A técnica é influenciada pelo local escolhido para a realização da punção. No entanto, nas punções de veia jugular interna e subclávia, dá-se preferência por realizar o procedimento no lado direito, pois está relacionado a menores riscos para o paciente visto que, a cúpula pleural é mais baixa, significando menor risco de pneumotórax, o trajeto até o átrio direito é mais retilíneo levando a uma menor possibilidade de mal posicionamento do cateter e o ducto torácico desemboca na veia subclávia à esquerda, proporcionando menor risco de quilotórax (1).

Cabe salientar as vantagens de realizar a punção de veia central com o auxílio de ultrassonografia para a visualização direta do vaso puncionado, reduzindo as potenciais complicações do procedimento $(1,6)$. No entanto, como a realidade da prática profissional nem sempre possibilita o uso de tal tecnologia, neste capítulo abordaremos os procedimentos da maneira tradicional, às cegas.

As particularidades de cada técnica em função do local escolhido serão descritas a seguir.

\subsection{1 - Veia Jugular interna: $(1,6-8,10,11)$}

Esta veia tem sido indicada como via de acesso preferencial em pacientes graves pela maioria dos autores (7). O correto posicionamento é com o médico na cabeceira da cama e o paciente com cabeça virada para o lado oposto do local alvo (10). O local da punção é no triângulo de Sedilot (1): o ápice do triângulo é formado pela clavícula com as duas cabeças do músculo esternocleidomastoideo. A base do triângulo se dá pela clavícula e as laterais pelas porções esternal e clavicular do músculo esternocleidomastoideo $(1,6,7,10)$. A agulha é apontada para o mamilo ipsilateral (10). Como já citado, o lado preferencial é o direito (Figura 2).

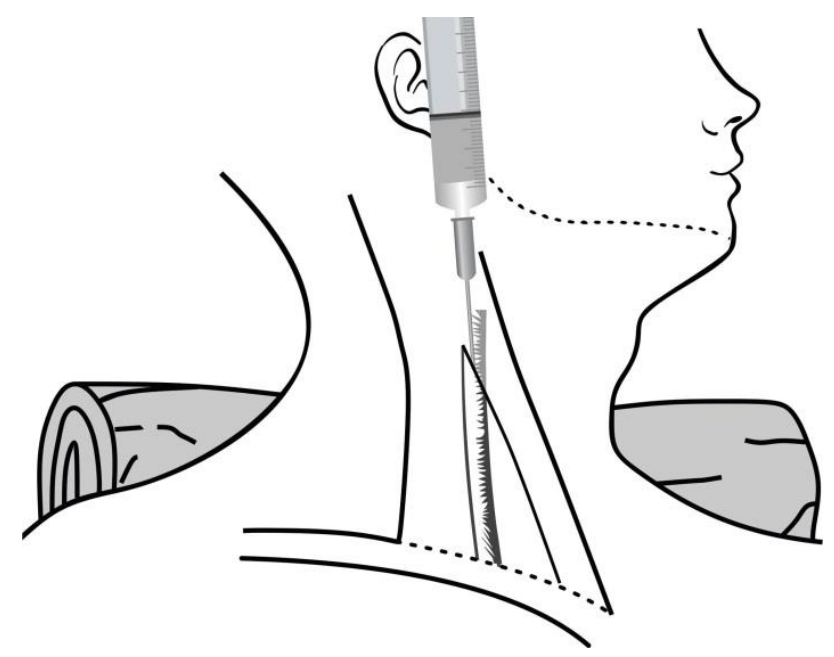

Figura 2 - Triângulo de Sedilot - Relações anatômicas para punção da veia jugular. Fonte: Elaborado por Gabriel Rigatti e Daniel Audino

- Separar os materiais necessários, explicar o procedimento ao paciente, auscultar o tórax do paciente a fim de verificar a presença de murmúrio vesicular simétrico bilateralmente;

- Posicionar o paciente em decúbito dorsal horizontal com a cabeça $30^{\circ}$ abaixo do corpo - posição de Trendelemburg (Figura 3 ) - com coxins abaixo das escápulas, deixando a cabeça estendida e rotada para o lado oposto ao da punção; 


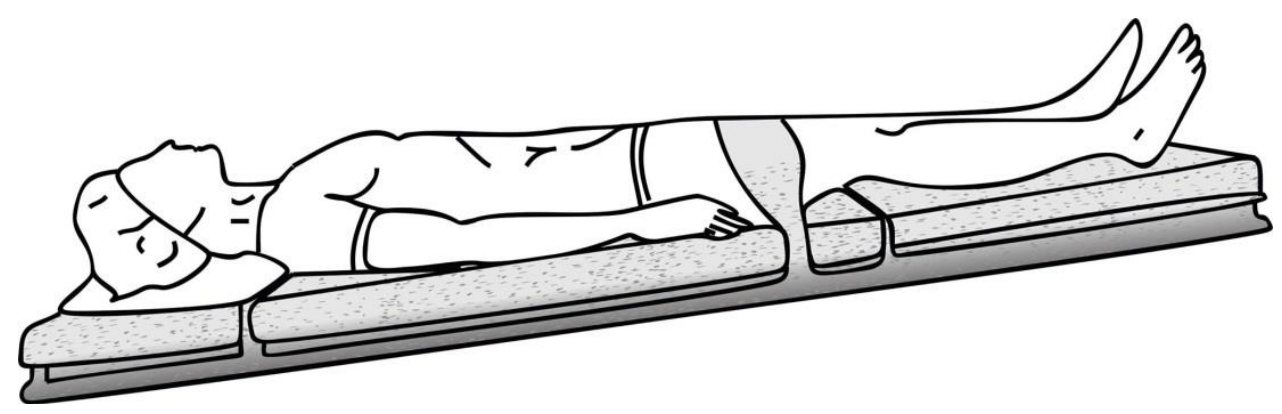

Figura 3 - Posição de Trendelemburg. Fonte: Elaborado por Gabriel Rigatti e Daniel Audino

- Realizar higienização das mãos, vestir máscara, gorro, avental cirúrgico estéril e luvas estéreis;

- Realizar a antissepsia no local da punção com solução à base de clorexidina, com auxilio de gaze estéril e pinça, realizando movimentos circulares do centro em direção à periferia;

- Colocar o campo estéril sobre o paciente, atentando para deixar o local da punção à mostra através da fenestra no campo;

- Anestesiar o local da punção (vide capítulo “Anestésicos locais”);

- Puncionar o local, introduzindo a agulha pouco acima do ápice do triângulo em ângulo de 30 a 40 graus em relação ao plano coronal e em direção ao mamilo ipsilateral, aplicando sucção leve até atingir a veia, evidenciado pelo refluxo de sangue pela seringa;

- Desconectar a seringa, ocluindo a extremidade da agulha com o dedo e introduzir o fio guia dentro da agulha. Importante observar o monitor cardíaco, pois qualquer alteração dos batimentos deve-se tracionar o fio guia até os batimentos normalizarem, pois a introdução excessiva do fio guia pode chegar ao átrio direito causando alterações cardíacas;

- Remover a agulha, mantendo o fio guia inserido no lúmen da veia. Faz-se então uma pequena incisão de 1-2 mm para introduzir o dilatador sobre o fio guia;

- Após dilatação do trajeto, remover o dilatador e introduzir o cateter sobre o guia.

- Retirar o fio guia e, após observar o refluxo de sangue para o cateter, conecta-se o cateter ao equipo contendo soro fisiológico $0,9 \%$. Caso não se observe refluxo de sangue, deve-se aspirar através do cateter ou abaixar a bolsa de soro ligada ao equipo abaixo do nível da punção a fim de observar se o procedimento foi efetivo e se a veia foi cateterizada. Só após a confirmação do cateter estar no lúmen da veia é que se inicia a infusão de qualquer substância. Caso não seja observado o refluxo de sangue, deve-se realizar novamente o procedimento;

- Estando o cateter na posição correta, deve-se proceder sua fixação com fio de sutura e realizar o curativo estéril no local;

- Ao fim do processo deve-se realizar um exame radiológico para verificar a posição do cateter. Este deve estar com sua extremidade localizada no átrio direito no $2^{\circ}$ ou $3^{\circ}$ espaço costal à direita.

\subsection{2 - Veia subclávia $(1,6-8,10,11)$}

A abordagem mais comum para o cateterismo da veia subclávia é a abordagem infraclavicular (10). Para realização desse procedimento deve-se identificar e demarcar a linha coraco-clavicular (linha que vai da borda superior da cabeça medial da clavícula à 
borda inferior do processo coracóide). Após, deve-se demarcar a linha infraclavicular e então identificar o ponto de cruzamento da linha coraco-clavicular com a linha infraclavicular (geralmente, na região médio-clavicular), e marcar um outro ponto cerca de $1,5 \mathrm{~cm}$ (uma polpa digital) para fora do cruzamento das duas linhas. A veia subclávia encontra-se, geralmente, paralela à linha coraco-clavicular, por baixo da clavícula, justamente medial ao ponto hemiclavicular (7). Mas, resumidamente, pode-se localizar a veia subclávia através da punção no terço médio da clavícula (Figura 4).

Importante ressaltar que uma das principais vantagens da cateterização dessa veia é que no estado de choque hipovolêmico ela dificilmente colaba, sendo mais facilmente cateterizada. No entanto, apresenta maiores riscos de complicações, como pneumotórax. Dessa forma, deve-se analisar individualmente cada caso e pesar riscos e benefícios do procedimento.

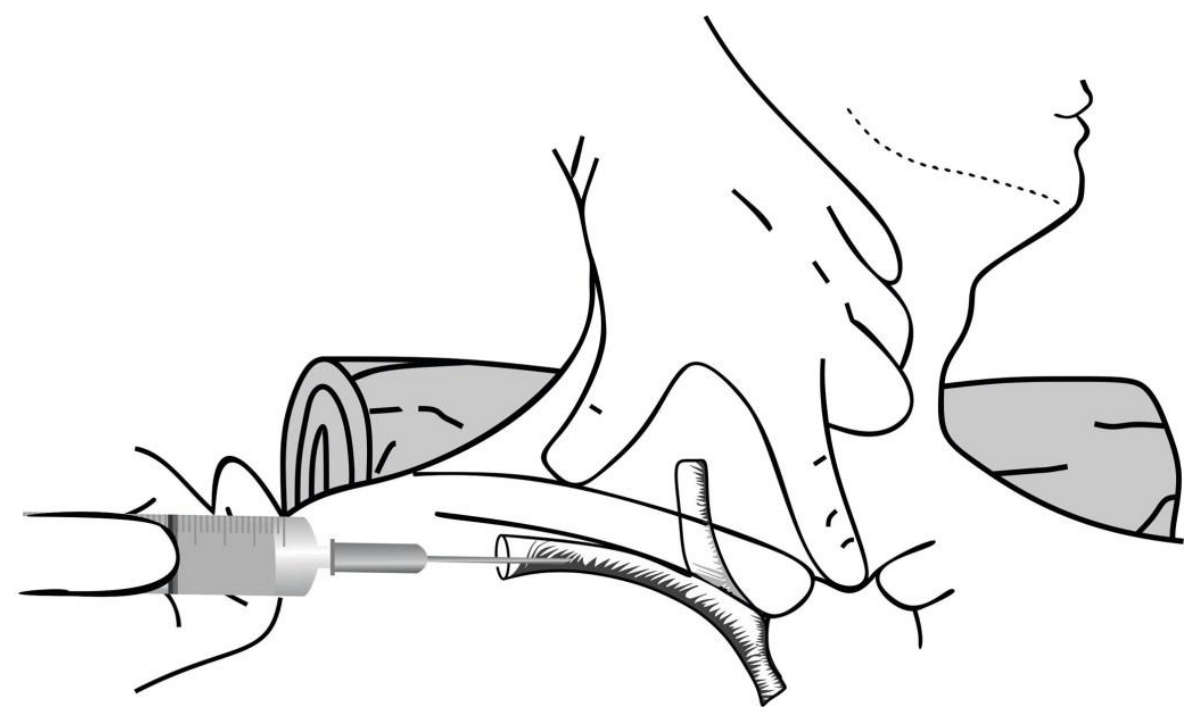

Figura 4 - Relações anatômicas para punção da veia subclávia. Fonte: Elaborado por Gabriel Rigatti e Daniel Audino

- Separar os materiais necessários, explicar o procedimento ao paciente;

- Posicionar o paciente em decúbito dorsal horizontal com a cabeça $30^{\circ}$ abaixo do corpo na posição de Trendelemburg com o pescoço levemente estendido contralateralmente à punção;

- Realizar higienização das mãos, vestir máscara, gorro, avental cirúrgico estéril e luvas estéreis;

- Realizar a antissepsia no local da punção com solução à base de clorexidina, com auxilio de gaze estéril e pinça, realizando movimentos circulares do centro em direção a periferia;

- Colocar o campo estéril sobre o paciente, atentando para deixar o local da punção à mostra através da fenestra no campo;

- Anestesiar o local da punção;

- Puncionar o local, introduzindo a agulha na junção do terço médio com o terço medial da clavícula. $O$ bisel da agulha deve estar em posição caudal. A agulha deve ser inserida num ângulo de 30 graus com a pele até a passagem pela clavícula. A partir desse ponto, a agulha deve ser inclinada a 10 a 15 graus e direcionada para a fúrcula esternal;

- Desconectar a seringa, ocluindo a extremidade da agulha com o dedo e introduzir o fio guia dentro da agulha;

- Remover a agulha, mantendo o fio guia inserido no lúmen da veia. Faz-se então uma pequena incisão de 1-2 mm para introduzir o dilatador sobre o fio guia; 
- Após dilatação do trajeto, remover o dilatador e introduzir o cateter sobre o guia;

- Retirar o fio guia e, após observar o refluxo de sangue para o cateter, conecta-se o cateter ao equipo contendo soro fisiológico $0,9 \%$ ou outra substância a ser infundida;

- Estando o cateter na posição correta, deve-se proceder a fixação do cateter com fio e, por fim, realizar o curativo estéril no local.

- Ao fim do processo deve-se realizar um exame radiológico para verificar a posição do cateter. Este deve estar com sua extremidade localizada no átrio direito no $2^{\circ}$ ou $3^{\circ}$ espaço costal à direita.

OBS: A veia subclávia também pode ser puncionada por via supraclavicular, mas este tipo de acesso é pouco utilizado na prática clínica, por ser de alto risco. A agulha é introduzida rente à borda superior interna da clavícula, na bissetriz do ângulo formado por esta e o bordo medial do músculo esternocleidomastoideo, sendo direcionada para um ponto entre o mamilo contralateral ou porção média do manúbrio esternal.

\subsection{3 - Veia femoral: $(1,5-8,11)$}

Em sua posição usual, encontra-se em posição medial à artéria femoral, dessa forma deve-se localizar o pulso femoral e realizar a punção $5 \mathrm{~mm}$ medialmente (Figura 5). Outra forma de identificar o local correto é encontrar o ponto médio entre a espinha ilíaca anterossuperior e a sínfise púbica. A punção deve ser feita $2-3 \mathrm{~cm}$ abaixo do ligamento inguinal. $(1,6,7,11)$

O paciente deve ser posicionado em decúbito dorsal horizontal, com a coxa fixada em ligeira rotação externa. Pode-se colocar um coxim sob a região lombo-sacral, para leve extensão $(1,11)$. Esta veia é pouco utilizada para acessos prolongados, por apresentar um alto índice de complicações, como infecções e trombose (7).

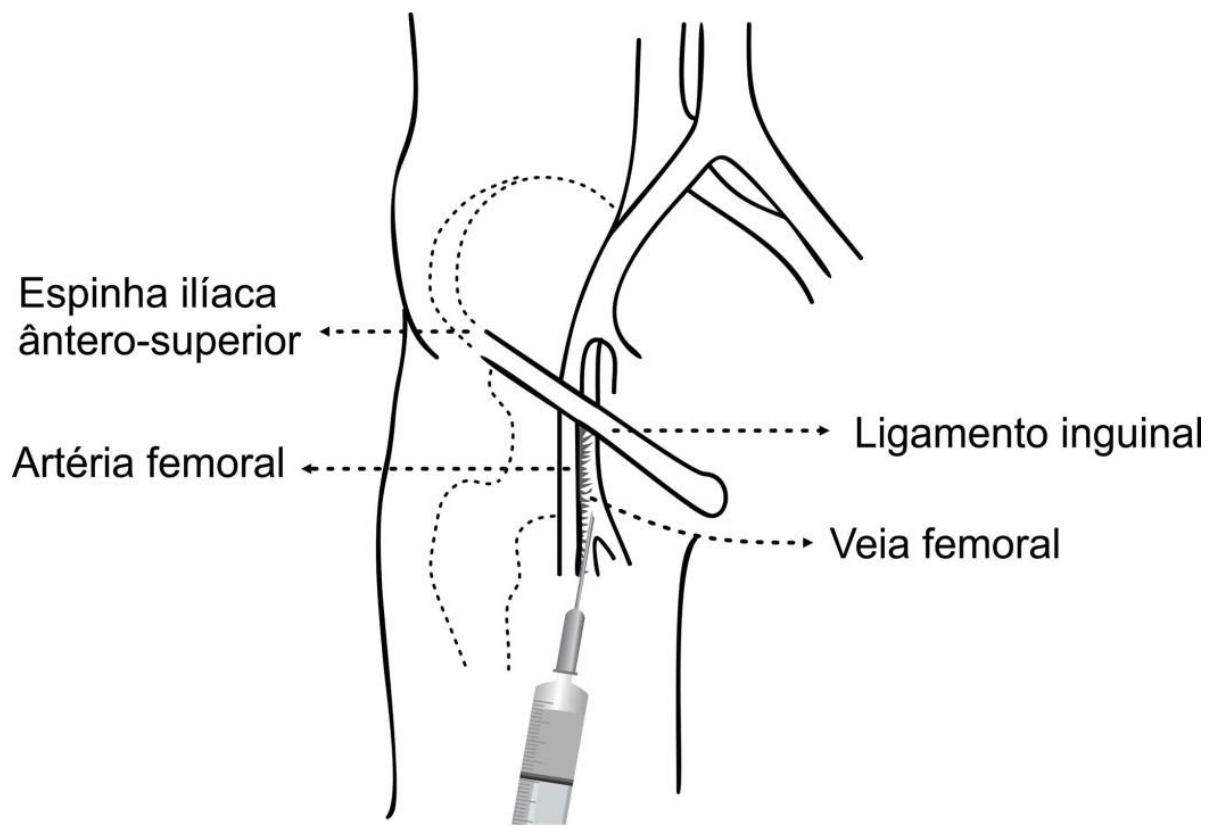

Figura 5 - Posição anatômica para punção da veia femoral. Fonte: Elaborado por Gabriel Rigatti e Daniel Audino

- Separar os materiais necessários e explicar o procedimento ao paciente;

- Posicionar o paciente em decúbito dorsal horizontal com a coxa fixada em ligeira rotação externa. Pode-se colocar um coxim sob a região lombo-sacral para proporcionar leve extensão; 
- Realizar higienização das mãos, vestir máscara, gorro, avental cirúrgico estéril e luvas estéreis;

- Realizar a antissepsia no local da punção com solução a base de clorexidina, com auxilio de gaze estéril e pinça, realizando movimentos circulares do centro em direção a periferia;

- Colocar o campo estéril sobre o paciente, atentando para deixar o local da punção à mostra através da fenestra no campo;

- Anestesiar o local da punção;

- Puncionar o local previamente identificado. A seringa com a agulha deve ser inserida paralelamente à artéria femoral, em um ângulo de 45 graus e em direção ao umbigo do paciente;

- Desconectar a seringa, ocluindo a extremidade da agulha com o dedo e introduzir o fio guia dentro da agulha;

- Remover a agulha, mantendo o fio guia inserido no lúmen da veia. Introduzir, então, o dilatador sobre o fio guia;

- Após dilatação do trajeto, remover o dilatador e introduzir o cateter sobre o fio guia;

- Retirar o fio guia e, após observar o refluxo de sangue para o cateter, conecta-se o cateter ao equipo contendo soro fisiológico $0,9 \%$ ou fluido a ser infundido no paciente;

- Estando o cateter na posição correta, deve-se proceder a fixação do cateter com fio e, por fim, realizar o curativo estéril no local;

- Ao fim do processo deve-se realizar um exame radiológico para verificar a posição do cateter. Este deve estar com sua extremidade localizada na junção da veia cava inferior com o átrio direito ou na altura da segunda vértebra lombar, caso o equipamento não tenha comprimento suficiente para alcançar a posição central.

\subsection{Complicações $(1,6-9,11,12)$}

As complicações desse procedimento podem ser mecânicas, infecciosas e tromboembólicas.

- As mecânicas incluem punção arterial, hematoma, pneumotórax, hemotórax, quilotórax e arritmias cardíacas.

- As tromboembólicas podem ocorrer do primeiro ao último dia de permanência do acesso e engloba os tromboembolismos e as embolias gasosas. $\mathrm{O}$ maior risco para trombose está relacionado com acesso de veias dos membros inferiores, como a femoral.

- Há também o risco de infecção do cateter, por isso as medidas de precaução devem ser tomadas, para diminuir o risco de infecção.

Importante ressaltar que assim que possível o cateter deve ser retirado a fim de minimizar os riscos de complicações inerentes a esse procedimento.

\section{Intraósseo}

Esse tipo de cateterização proporciona rápido acesso ao plexo venoso da medula óssea que se conecta com a circulação venosa sistêmica, proporcionando uma via segura para administração de fluidos, drogas e hemoderivados numa situação de emergência (1). Essa técnica é utilizada principalmente em crianças, porém não existe idade máxima ou restrição para o uso em adultos.

\subsection{Local de escolha $(1,12-15)$}

O local para punção mais frequentemente usado em crianças corresponde à face interna 
da tíbia proximal (12-14), pois possui pouco tecido subcutâneo e não interfere nas manobras de ressuscitação, como massagem cardíaca e ventilação mecânica (1). O melhor local fica 1-3 cm abaixo da tuberosidade da tíbia. Ainda em crianças, outros locais podem ser utilizados como o fêmur distal, o úmero proximal e o calcâneo. Em adultos, além da tíbia, pode-se optar por realizar o procedimento no maléolo medial, esterno, clavícula e crista ilíaca $(1,12-15)$.

O acesso intraósseo não colapsa em caso de choque e a medula óssea presente segmentos metafisários dos ossos longos é ricamente vascularizada, sendo capaz de transportar drogas e fluidos aplicados para o sistema vascular central rapidamente (Figura 6). Este acesso, portanto, permite a administração de medicamentos, volume e hemoderivados de uma maneira fácil, rápida e segura. Os tempos de transporte são relatados como 1 a 2 minutos, mesmo durante a RCP com compressões torácicas (12).

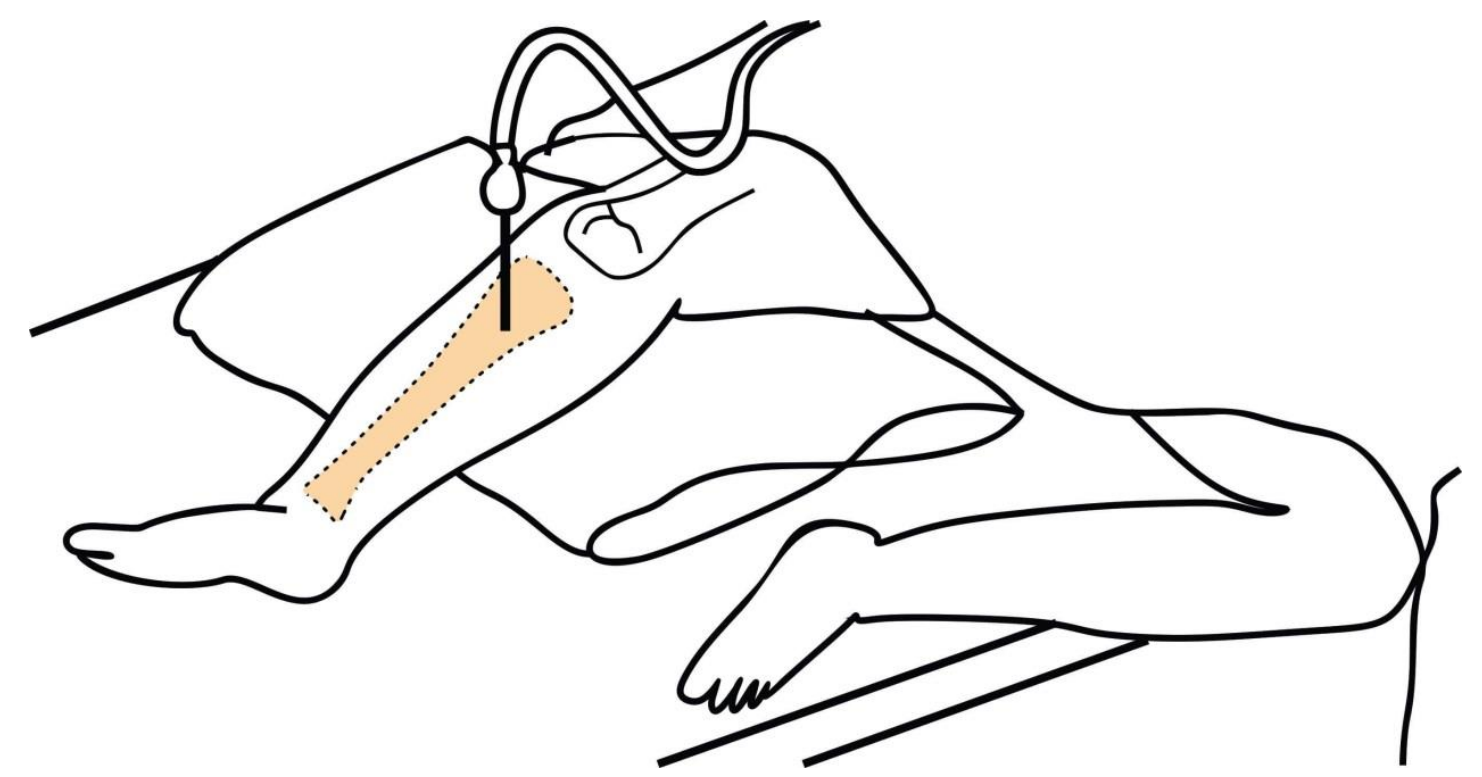

Figura 6 - Desenho de acesso intraósseo. Fonte: Elaborado por Gabriel Rigatti e Daniel Audino

\subsection{Indicações $(1,12,14,15)$}

Pode ser realizado no caso de não se conseguir um acesso periférico rápido em pacientes em situação de emergência.

\subsection{Contraindicações $(1,12,14,15)$}

- Puncionar locais com ossos fraturados;

- Membros com a presença de próteses;

- Infecção de pele ou partes moles subjacentes ao local de punção;

Não se aconselha fazer em pacientes com osteoporose pelo maior risco de fraturas.

\subsection{Vantagens $(1,12-15)$}

- Procedimento rápido, levando em média alguns minutos dependendo da experiência do profissional;

- Seguro por ter baixos riscos e poucas complicações;

- É uma alternativa caso não se consiga rapidamente um acesso venoso;

- Além disso, apesar se ser mais usada em crianças, essa técnica também pode ser 
utilizada em adultos, não tendo idade mínima ou máxima para sua execução;

- Vantagem anatômica da medula óssea por funcionar como uma veia rígida que não colaba em estados de hipovolêmicos.

\subsection{Desvantagem: $(1,12-15)$}

- O acesso intraósseo obtido em situações de emergência pode ser mantido, de preferência, por 24 horas após sua inserção, depois desse período, o acesso paulatinamente perde sua eficácia e aumentam os riscos de embolia gordurosa e osteomielite.

- O local só poderá ser puncionado ou exposto a tentativa uma única vez, pois os fluidos e medicações infundidos podem não atingir a circulação central por extravasarem, podendo resultar em uma síndrome compartimental.

\subsection{Escolha do cateter $(1,12-15)$}

E escolha em crianças será baseada no tamanho do paciente. O procedimento pode ser realizado com uma agulha comum de injeção tamanho $25 \times 12$, agulha para raquianestesia, agulha com trepano para biópsia de medula óssea, agulha intraóssea tamanho 18 a 22 para menores de 18 meses e de 13 a 16 para crianças maiores (15). Em adultos existem materiais próprios para realização desse procedimento, como o sistema EZ-IO da Vidacare Corporation, utilizado para acessos intraósseos periféricos e o F.A.S.T 1, que é um dispositivo para acesso esternal (12). No entanto, como estes dispositivos não estão facilmente disponíveis, pode-se substituí-los pelas agulhas supracitadas (13).

\subsection{Técnica $(1,14,15)$}

Materiais:

- Luvas estéreis;

- Gorro e máscara;

- Solução para assepsia local;

- Gaze estéril e pinça;

- Anestésico local;

- Solução salina estéril e solução salina heparinizada;

- Agulha para punção;

- Tala para imobilizar o membro e coxim para apoio;

- Equipos de infusão de soluções;

- Material para curativo;

Procedimento:

- Separar os materiais necessários, explicar o procedimento ao paciente ou aos familiares, realizar higienização das mãos, vestir máscara, gorro e luvas estéreis;

- Posicionar o paciente em decúbito dorsal horizontal, imobilizar o membro com uma tala ou solicitar auxílio para imobilização e, como suporte, pode-se utilizar um coxim sob a fossa poplítea;

- Realizar a antissepsia no local da punção utilizando gaze estéril e pinça, realizando movimentos circulares do centro em direção à periferia;

- Anestesiar o local da punção;

- Puncionar o local exercendo uma pressão firme, inserindo a agulha perpendicularmente ao plano ósseo. Caso a punção seja em uma criança, deve-se inclinar 
a agulha a 15 a 30 graus e direcioná-la para posição distal ao local da punção para evitar a cartilagem de crescimento localizada na metáfise óssea; exerce-se pressão até sentir diminuição da resistência, nesse momento, para verificar a posição correta deve-se perceber se a agulha fica fixa no local, sem necessidade de sustentação. Também podese conectar uma seringa a fim de aspirar material medular, porém mesmo estando na posição correta nem sempre essa aspiração é possível. Para confirmação pode-se injetar 5 a $10 \mathrm{ml}$ solução salina para observar resistência ao fluxo e se há extravasamento de líquido para os sítios que circundam o local da punção, não havendo tem-se a confirmação da posição;

- Retirar o guia de dentro da agulha, conectar a seringa e aspirar conteúdo para obter material medular para análises laboratoriais cabíveis;

- Lavar a agulha com solução heparinizada e conectar o equipo para infusão;

- Fixar o equipo ao paciente e, não havendo nenhum extravasamento, deve-se fixar a agulha com esparadrapo para evitar abalos;

- Dispensar adequadamente todos os materiais utilizados, deixar o paciente em posição confortável, retirar os equipamentos de segurança e higienizar as mãos.

Complicações $(1,14,15)$

- Dor local;

- Infusão de fluídos no subcutâneo, secundariamente à colocação incorreta do cateter;

- Síndrome compartimental secundariamente ao extravasamento de líquido;

- Formação de coágulos na agulha;

- Necrose tecidual;

- Infecções no local como celulites e osteomielites;

- Ruptura dos tecidos ósseos;

- Entre outras complicações menos relatadas estão as lesões da cartilagem de crescimento em crianças, embolias gasosas e acometimentos torácicos como mediastinite e ferimentos em coração em vasos da base associados à punção no osso esterno.

Prática em situação de emergência

Em situações de emergência, como no trauma ou em uma ressuscitação cardiopulmonar (RCP), o acesso de escolha é o periférico, devendo-se permitir dois acessos em duas veias calibrosas utilizando cateteres curtos e grossos. Caso não se consiga um acesso com periférico, a via intraóssea deve ser considerada - esse procedimento é realizado mais frequentemente em crianças. Após a melhor estabilização do paciente deve-se realizar um acesso central para auxiliar na administração de fluidos, drogas e monitorar a pressão venosa central, entre outros procedimentos fundamentais para o manejo correto do paciente (1).

\section{Punção Arterial}

Neste capítulo, abordaremos a técnica de coleta do sangue arterial para análise dos parâmetros gasométricos, conhecida como gasometria arterial. A interpretação dos dados se encontra no capítulo "Gasometria arterial".

A punção arterial com fins de análise bioquímica é um procedimento muito comum em pacientes hospitalizados, especialmente em unidades de tratamento intensivo (UTI). Através dela são obtidas medidas do sangue arterial como $\mathrm{pH}$, pressão parcial de dióxido de carbono, pressão parcial de oxigênio, saturação da hemoglobina pelo oxigênio e excesso ou falta de bases plasmáticas, sendo o bicarbonato um exemplo. Estes parâmetros são fundamentais no tratamento de pacientes com distúrbios metabólicos ou respiratórios por proverem uma amostragem diária da oxigenação, ventilação alveolar e equilíbrio 
ácido-básico do paciente.

\subsection{Local de escolha}

São possíveis locais para a realização da punção as artérias radial, braquial, femoral e dorsal do pé. Para a escolha mais adequada, deve-se levar em consideração:

- A facilidade de acesso ao vaso;

- A integridade e sensibilidade dolorosa das estruturas adjacentes à artéria;

- A proximidade de vasos venosos;

- A presença de circulação colateral.

Assim, o sítio de punção mais frequentemente utilizado é a artéria radial, pois é de fácil acesso, encontra-se mais superficialmente na sua porção distal, não apresenta vasos importantes próximos e tem a artéria ulnar como corresponsável pela circulação sanguínea da mão. Para se certificar que o fluxo sanguíneo colateral está íntegro, é indicado a realização do teste de Allen (16). Se necessário, pode-se utilizar ultrassonografia doppler, pletismografia e exame de ressonância magnética para avaliar a circulação colateral (17).

\section{Teste de Allen}

Verifica a viabilidade da circulação colateral da artéria radial composta pelo fluxo sanguíneo da artéria ulnar. É realizado da seguinte forma $(16,17)$ :

- Com o antebraço do paciente na posição supina, pressione as artérias radial e ulnar até ocluir o fluxo sanguíneo;

- Peça ao paciente para fechar a mão firmemente repetidas vezes, por no máximo 30 segundos, a fim de drenar o sangue contido nos vasos da mão;

- Peça ao paciente para manter a mão aberta. A palma deve estar pálida;

- Retire os dedos que estavam pressionando a artéria ulnar, mas mantenha a pressão sobre a artéria radial;

- Se o teste de Allen for positivo: a circulação colateral, representada pelo fluxo sanguíneo da artéria ulnar, deve reperfundir os vasos da mão em menos de 10 segundos, sendo identificado pelo retorno da coloração avermelhada à palma da mão.

- Se o teste de Allen for negativo: o retorno da coloração avermelhada da palma da mão demora mais do que 10 segundos. Indica que a circulação colateral da artéria radial não está íntegra. Este resultado contraindica a realização de punção na artéria radial, pois havendo uma obstrução do fluxo sanguíneo desta (por exemplo, uma trombose após o procedimento), não haveria irrigação suficiente para a mão.

\subsection{Indicações:}

Atualmente, é considerado um procedimento de rotina em enfermarias e UTIs para auxiliar no diagnóstico e evolução de pacientes com desequilíbrio ácido-básico. Portanto, é indicada a realização de gasometria arterial de rotina em $(7,17)$ :

- Pacientes portadores de distúrbios metabólicos, como cetoacidose diabética, doença renal crônica e pancreatite aguda;

- Pacientes com insuficiência respiratória, como portadores de doença pulmonar obstrutiva crônica, pneumonia grave, com hiperventilação ou em uso de ventilação mecânica.

\subsection{Contraindicações $(7,17)$ :}


Teste de Allen negativo e presença de infecção sobre o sítio da punção, sendo indicado a realização em outra artéria.

Em pacientes em uso de anticoagulantes ou portadores de coagulopatias, deve-se avaliar o risco-benefício da realização da gasometria arterial.

\subsection{Vantagens:}

A gasometria arterial é um exame rápido e barato, cuja técnica é facilmente aprendida e aplicada (17).

\subsection{Desvantagens:}

- O procedimento pode ser desconfortável e doloroso;

- Pode ocorrer a formação de equimoses nos locais puncionados.

\subsection{Técnica $(7,16,17)$}

Materiais

- Luvas de procedimento;

- Álcool $70 \%$ para assepsia;

- Seringa heparinizada com $0,1 \mathrm{ml}$ de heparina;

- Gaze;

- Curativo;

- Agulha para anestesia e outra para punção.

Procedimento

- Higienizar as mãos, separar os materiais necessários, heparinizando a seringa com $0,1 \mathrm{ml}$ de heparina, explicar o procedimento ao paciente e acompanhantes e calçar luvas;

- Realizar o teste de Allen a fim de testar a irrigação colateral pelo fluxo da artéria ulnar;

- Limpar o local da punção com solução de álcool a 70\%;

- Realizar anestesia local. Essa etapa é controversa na literatura, mas por evitar a dor causada pelo procedimento é indicado realizar a anestesia.

- Estender o pulso do paciente, posicioná-lo em local plano e palpar a pulsação da artéria radial com o dedo indicador e o dedo médio. Usando os dedos como referência, pode-se afastá-los a fim de puncionar a artéria no espeço gerado pelo afastamento dos dedos;

- Puncionar a artéria com o bisel da agulha voltado contra o fluxo sanguíneo em um ângulo de $30^{\circ}$. Aspirar a seringa ao longo do trajeto de punção até que se alcance a artéria e o sangue preencha a seringa numa quantidade de aproximadamente $2 \mathrm{ml}$.

- Pressionar o local da punção por alguns minutos;

- Realizar a homogeneização do sangue com a heparina contida na seringa. Deve-se retirar as bolhas de ar existentes para que não altere o resultado da análise.

- Dispense os materiais utilizados nos locais adequados de descarte, retire as luvas, higienize as mãos e envie o material para análise laboratorial.

Importante: informações como uso de broncodilatadores, vasodilatadores e oxigenioterapia devem ser registrados no pedido do exame.

\subsection{Complicações $(7,17)$}




\section{Vittalle - Revista de Ciências da Saúde v. 33, n. 1 (2021) 67-83}

- Trombose da artéria puncionada;

- Infecção;

- Hematoma periarterial;

- Dor local.

Erros no procedimento que podem alterar os resultados (16)

- Punção venosa;

- Excesso de heparina na seringa;

- Bolhas na amostra;

- Contaminação da amostra com ar;

- Deixar amostra em temperatura ambiente e demorar para realizar a análise.

\section{Referências}

1. Carlotti APCP. Acesso Vascular. Revista da Faculdade de Medicina de Ribeirão Preto e do Hospital das Clínicas da FMRP Universidade de São Paulo 2012; 45(2): 208-14.

2. Pablo da Silva V. Punção venosa. Disponível em: <http://aenfermagem.com.br/materia/puncaovenosa/>.

3. Ministério da Saúde. Cuidados com acessos venosos: orientações para o cuidado com o paciente no ambiente domiciliar. Disponível em: $<$ http://portalarquivos2.saude.gov.br/images/pdf/2017/dezembro/21/10-Cuidados-com-AcessoVenoso.pdf $>$.

4. UFRN. Disciplina Medicina de Urgência: Trauma Clínico e Cirúrgico. Disponível em: <https://sites.google.com/site/monitoriadetraumaufrn/home/acesso-venoso-periferico〉.

5. Lopes, AC, Guimarães HP, Lopes RD. Acessos Venosos em Emergências Clínicas: Programa de atualização em medicina de urgência - Sociedade Brasileira de Clínica Médica. Porto Alegre: Artmed 2007. $160 \mathrm{p}$.

6. UFRN. Disciplina Medicina de Urgência: Trauma Clínico e Cirúrgico. Disponível em: <https://sites.google.com/site/monitoriadetraumaufrn/home/acesso-venoso-central>.

7. Araújo S. Acessos Venosos Centrais e Arteriais Periféricos - Aspectos Técnicos e Práticos. Rev Bras Ter Int 2003; 15(2): 70-82.

8. Ferrari D. Terapia Intensiva Moderna Básica: Acesso Venoso Central. Disponível em: <http://www.acls.com.br/sati-acessovenoso.htm>.

9. Parienti J, Mongardon N, Mégarbane B, Mira J, Kalon P, Gros A, et al. Intravascular Complications of Central Venous Catheterization by Insertion Site. N Engl J Med 2015; 373(13): 1220-9.

10. Akaraborworn O. A review in emergency central venous catheterization. Chin J Traum 2017; 20(3): $137-40$.

11. Taylor RW, Palagiri AV. Central venous catheterization. Crit Care Med 2007; 35(5):1390-6.

12. Leidel BA, Kirchhoff C, Bogner V, Stegmaier J, Mutschler W, Kanz. Is the intraosseous access route fast and efficacious compared to conventional central venous catheterization in adult patients under resuscitation in the emergency department? A prospective observational pilot study. Patient Safety In Surgery 2009; 3(1): 24-32.

13. Frascone RJ, Jensen JP, Kaye K, Salzman JG. Consecutive Field Trials Using Two Different Intraosseous Devices. Prehospital Emergency Care 2007; 11(2): 164-71.

14. Lane JC, Guimarães HP. Acesso venoso pela via intra-óssea em urgências médicas. Rev Bras Ter Int 2008; 20 (1): 63-7.

15. Figueiredo Junior I, Vidal de Carvalho, Macedo de Lima G. Punção e infusão intra-óssea 2014.

16. Viegas CAA. Gasometria Arterial. Jornal de Pneumologia 2012; 28(3): 233-8.

17. Dev, SP, Hillmer MD, Ferri M. Arterial Puncture for Blood Gas Analysis. N Engl J Med. 2011; 364(5): 7. 